\title{
Process induced residual stress effect on fatigue lifetime of automotive steel components
}

\author{
Elias Merhy ${ }^{1, a^{*}}$, Ngadia Taha Niane ${ }^{2, b}$, Bastien Weber ${ }^{3, \mathrm{c}}$ and Philippe Bristiele, \\ 1PSA Peugeot Citroën, Route de Gisy, 78943 Vélizy-Villacoublay Cedex, France \\ 2PSA Peugeot Citroën, 18 Rue des Fauvelles, 92250 Garenne Colombes Cedex, France \\ ${ }^{3}$ ArcelorMittal Maizières Research (S.A.), Voie Romaine, 57280 Maizières-lès-Metz, Cedex, \\ France \\ aelias.merhy@mpsa.com, bngadiataha.niane1@mpsa.com, cbastien.weber@arcelormittal.com, \\ dphilippe.bristiel@mpsa.com
}

\begin{abstract}
Keywords: welding residual stress, mechanical fatigue, lifetime prediction, automotive steel components
\end{abstract}

\begin{abstract}
Metal Active Gas (MAG) welding process of steel sheets generates, in the vicinity of the welding joint, the well-known Heat Affected Zone (HAZ) in which the material presents more microstructural defects compared to the original metal. Since high cycle fatigue is largely dependent on the material microstructure features, the HAZ is considered as the weakest zone under high cycle fatigue loading. In addition, the welding causes, in the Heat Affected Zone, irreversible plastic strains that induce important residual stress fields in this critical zone of the structure. Therefore, in order to properly predict the high cycle fatigue lifetime of the welded automotive components, it is of primordial importance to first identify and then consider, if necessary, the welding induced residual stress field in the structure modeling. In this work, it is found that process induced residual stress has a negligible effect on both high cycle fatigue and low cycle fatigue domains.
\end{abstract}

\section{Introduction}

Automotive chassis and suspension parts are usually manufactured from steel sheet blanks undergoing a forming process (e.g. simple folding, stamping or hydro-forming) and then assembled by several welded joints (e.g. standard arc-, spot- and laser-weld). Currently, a single steel body-inwhite is achieved thanks to at least 1000 spot welds, whereas front and rear suspensions are seamwelded on an overall length of several 1000s millimetres. Within this framework, modelling of welded assemblies is of prior concern. Fatigue strength assessment naturally focuses on welded assemblies, which constitute the structure critical zones under fatigue loading. In fact, the welding process leads to changes in the material mechanical and microstructural properties at a small area in the vicinity of the welded joint. In this area, called "heat-affected zone" or HAZ, the material presents more microstructural defects compared to the original metal. Consequently, the HAZ is considered as the structure critical zone under fatigue loading, since high cycle fatigue phenomenon is largely dependent on the material microstructure defects. However, welding process causes not only properties modifications in the HAZ, but also material plastic deformation that induces an important residual stress field, and that, in the structure critical zone. These residual stress fields may have a pronounced influence on the welded structure lifetime, as mentioned by several authors [1-3]. Hence, an optimal fatigue lifetime prediction of the automotive components requires a good knowledge of the welding induced residual stress field at the structure modelling stage.

Thus, experimental analysis has been carried out on several MAG welded assembly specimens. For a first specimens batch, a tempered heat treatment process has been conducted in order to relieve residual stresses. For the second batch, the specimens have been left as-welded. For both specimen batches, residual stress has been measured using x-ray diffraction at different points in the HAZ. Several fatigue tests have been realised on all as-welded and heat treated specimens in order to characterise the effect of residual stress on fatigue lifetime, as studied by several authors [4-6]. In addition, microstructural observations (material phases) and micro-hardness measurements have 
been carried out on all specimens. Finally residual stress fields have been numerically calculated by simulating the welding process under Sysweld code. Initial and boundary conditions of the welding process simulation have been calibrated by comparing numerical results to experimental ones, namely the residual stress, the material phases and the weld pool size and shape.

Based on the overall analysis, it has been found that residual stresses have almost no effect on the fatigue lifetime, and that for both low cycle fatigue and high cycle fatigue ranges. Thus, welding induced residual stresses may be not taken into account in the fatigue life estimation of MAG welded components (e.g. suspension automotive components).

\section{X-ray residual stress measurement}

Residual stress measurement has been conducted on three welded specimen geometries $\mathrm{T}$ joint, lap joint and torsion joint (Fig. 1) by using x-ray diffraction technique. The spot size of the used collimator is $1 \mathrm{~mm}$; thus the nearest possible distance between the spot centre and the bead toe is $0.5 \mathrm{~mm}$ (cf. Fig. 1). The used measurement technique is the conventional sin2psi method with $\mathrm{Cr}-$ $\mathrm{K} \alpha$ radiation. The measurement uncertainty is estimated at $\pm 30 \mathrm{MPa}$. The two grades of steel FB600 $\left(R_{\mathrm{p} 0.2}=452 \mathrm{MPa} ; R_{\mathrm{m}}=729 \mathrm{MPa} ; A_{5}=17.2 \%\right)$ and CP800 $\left(R_{\mathrm{p} 0.2}=676 \mathrm{MPa} ; R_{\mathrm{m}}=979 \mathrm{MPa} ; A_{5}=\right.$ $9.7 \%$ ) have been used for the T joint geometry. For the two other geometries, only the grade FB600 has been used. Then, a specimen batch corresponds to four specimens.
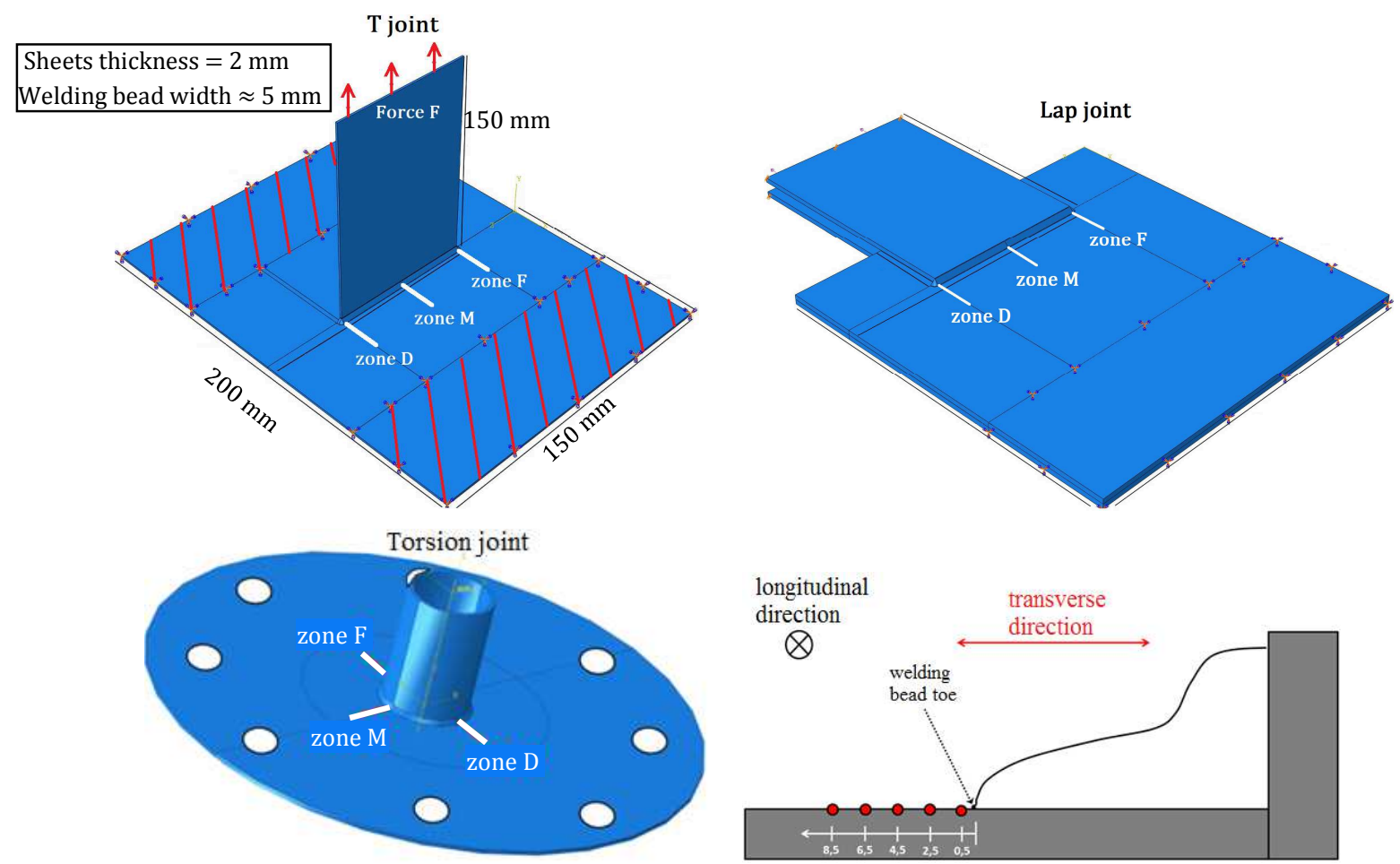

Figure 1. Zones of residual stress measurements for all three specimen geometries.

Two different specimen batches have been analysed in this work; for the first batch, a thermal stress relief treatment $\left(600^{\circ} \mathrm{C} / 20\right.$ minutes) is conducted; the second batch is kept as-welded. For both specimen batches, transverse residual stresses (see transverse direction in Fig. 1) have been measured at different surface points in front of the welding bead toe. Graphics of Fig. 2 show that welding induced transverse residual stresses have relatively high values. In addition, these stresses are essentially positives (tension stresses) which may shorten the fatigue lifetime. Only lap joint specimens show negative residual stresses. In the bead toe vicinity, residual stress highest values are always reached at the end of the welding bead (zones F). 

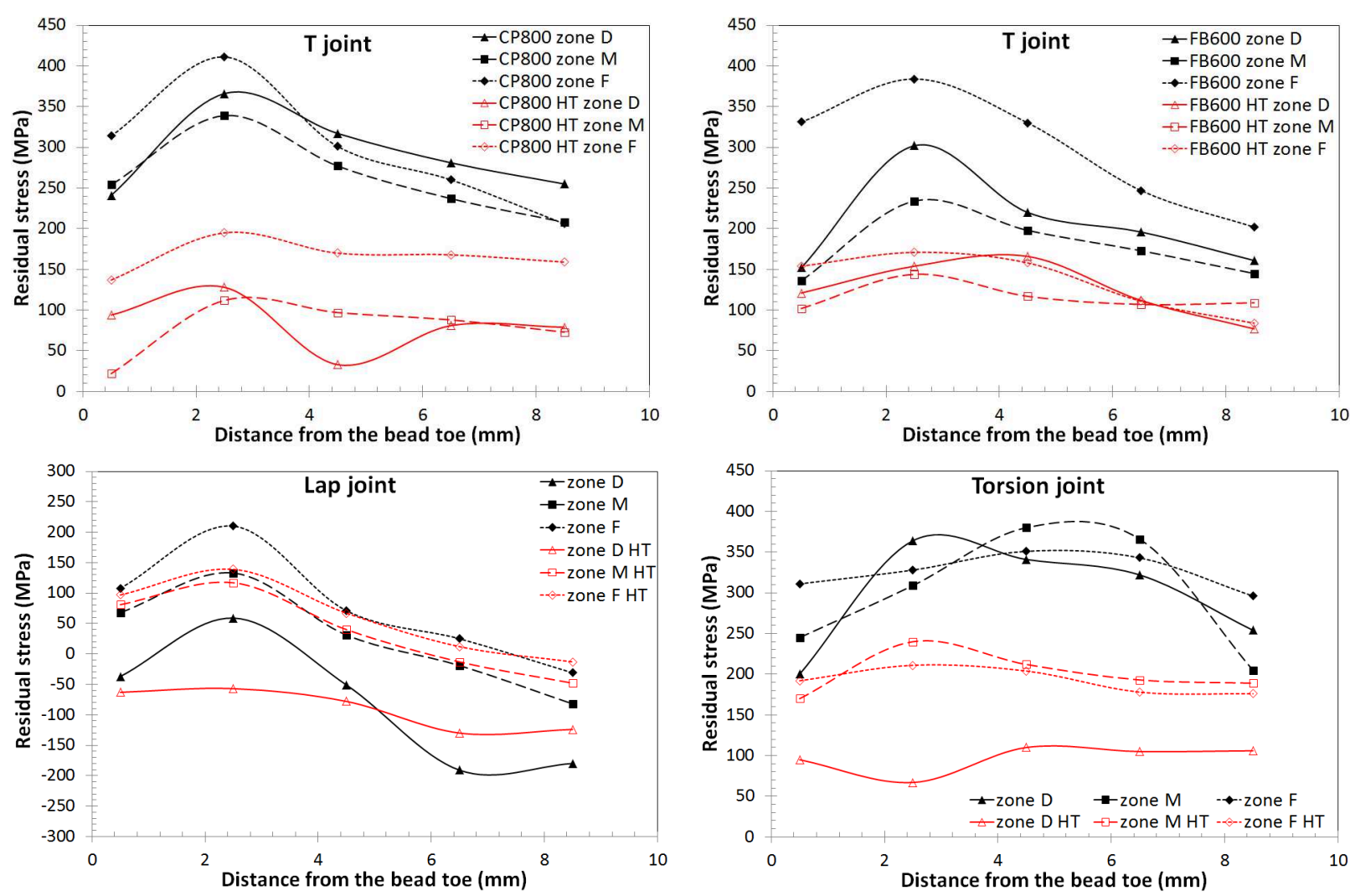

Figure 2. Results of residual stress measurement for all batches specimens; HT designates the relieved stress heat treated specimens.

These graphics show that, when moving away from the bead toe, residual stresses increase and then decrease. Finally, Fig. 2 results show that heat treatment considerably reduces residual stresses by recrystallization.

\section{Numerical residual stress estimation by welding process simulation}

During the welding process, several physical phenomena (thermal, metallurgical, mechanical) have to be considered by the numerical modelling in order to predict the residual stresses fields and then the distortion of the structure. A methodology based on three-dimensional finite element modelling and using Sysweld code has been developed to compute the distortions due to welding of automotive parts highly jointed. The simulation is divided into two steps. First a transient thermometallurgical coupled calculation is performed, giving that a strong coupling exists between temperature and metallurgical properties. The result of this calculation is used in a second step mechanical calculation to determine the distortion and the residual stress of the whole structure. The interaction between mechanical properties and thermal/metallurgical ones are neglected since there is a slight coupling between them.

The thermo-metallurgical analysis is based on the resolution of the modified heat equation taking into account the latent heat of fusion/solidification and the phase transformation heat in the solid state $[7,8]$ :

$$
\rho C \frac{\partial T}{\partial t}=\nabla(\lambda \nabla T)-\sum_{i<j} L_{i j} A_{i j}
$$

where, $L_{i j}(T)$ is the latent heat of the $i$ to $j$ phase transformation, $A_{i j}$ is the proportion of phase $i$ which is transformed into phase $j$ by unit time. Specific heat $C$ and conductivity $\lambda$ are evaluated according to the proportions of the various phases: 


$$
C=\sum_{i} x_{i} C_{i}, \lambda=\sum_{i} x_{i} \lambda_{i} \text { and } \sum_{i} x_{i}=1
$$

The specific heats of the phases $C_{i}$, and the transformation heats $L_{i j}$ are calculated as functions of the phase enthalpies $H_{i}$ and $H_{j}$ as follows:

$$
C_{i}=\frac{\mathrm{d} H_{i}}{\mathrm{~d} T} \text { and } L_{i j}=H_{j}-H_{i} .
$$

To solve the heat equation, the thermal properties of each single phase of the material are needed. During the analysis, these properties evolve with the temperature.

The power density needed to melt the filler material is modelled as a three-dimensional heat source $Q(x, y, z)$ moving along the welding trajectory. The source is assumed to have a "two halfellipsoid" shape which is the shape commonly used in case of MIG/MAG modelling. Heat source parameters are identified by calibration on macrograph via several test cases.

For phase transformations involving diffusion for steels (austenite, ferrite and bainite), the Leblond [9] model is used. In case of FB600 steel, the metallurgical transformations to consider are the austenitic one during heating and the ferritic, bainitic and martensitic ones during cooling.

The mechanical analysis has been performed using a thermo-elastoplastic isotropic hardening computational model. The influence of the thermo-metallurgical properties on mechanical ones is taken into account by the mean of numerous parameters. The evolution of yield stress and expansion/contraction parameters according to temperature is obtained by averaging the values of these parameters for all phases according to their proportions. The transformation plasticity is determined using the model of Leblond $[10,11]$. The Poisson's ratio has little influence and is supposed to be constant [12].

Fig. 3 shows macrographs from mid-section of the welding bead in which a comparison is shown between experimental and numerical simulation of the weld pool and the HAZ shapes. The numerical simulation results are represented by the drawn curves. The weld pool zone is numerically identified using as a threshold the melting temperature $\left(1505^{\circ} \mathrm{C}\right)$. While the $\mathrm{HAZ}$ is delimitated by using the temperature of austenitisation $\left(867^{\circ} \mathrm{C}\right)$. Fig. 3 macrographs show good agreement between experimental and numerical shapes of the weld pool and HAZ. These results are used to validate the thermal part of the model.
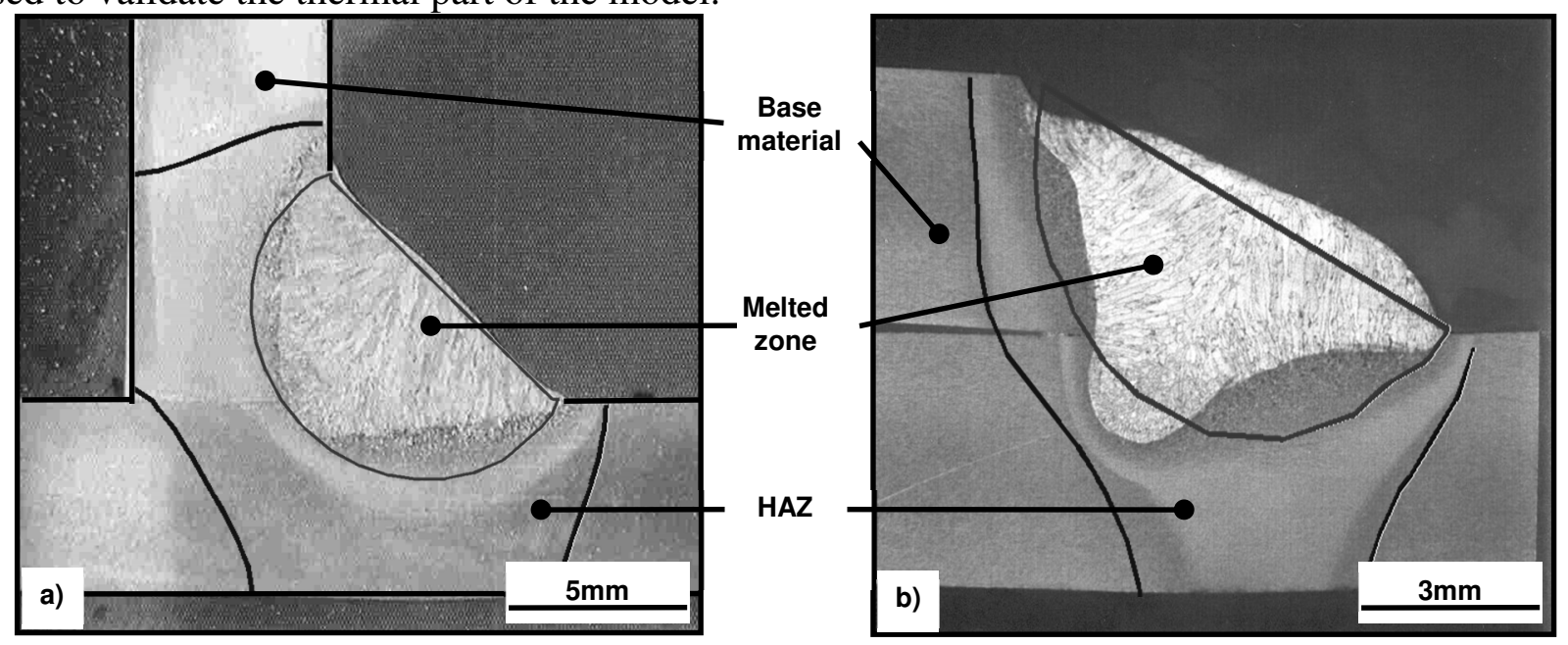

Figure 3. Comparison between experimental and numerical simulation of the weld pool and HAZ shapes; a) $\mathrm{T}$ joint and b) overlapping joint.

Additionally, welding process simulation has led to the identification of the residual stress field in the vicinity of the welding bead. As in the experimental case, numerical results show (Fig. 4) an increase followed by a decrease of the transverse residual stress values when going from the bead toe toward the specimen edge in the transverse direction (Fig. 1). Generally, Fig. 4 shows that numerical curves have the same allure of that of experimental ones. 

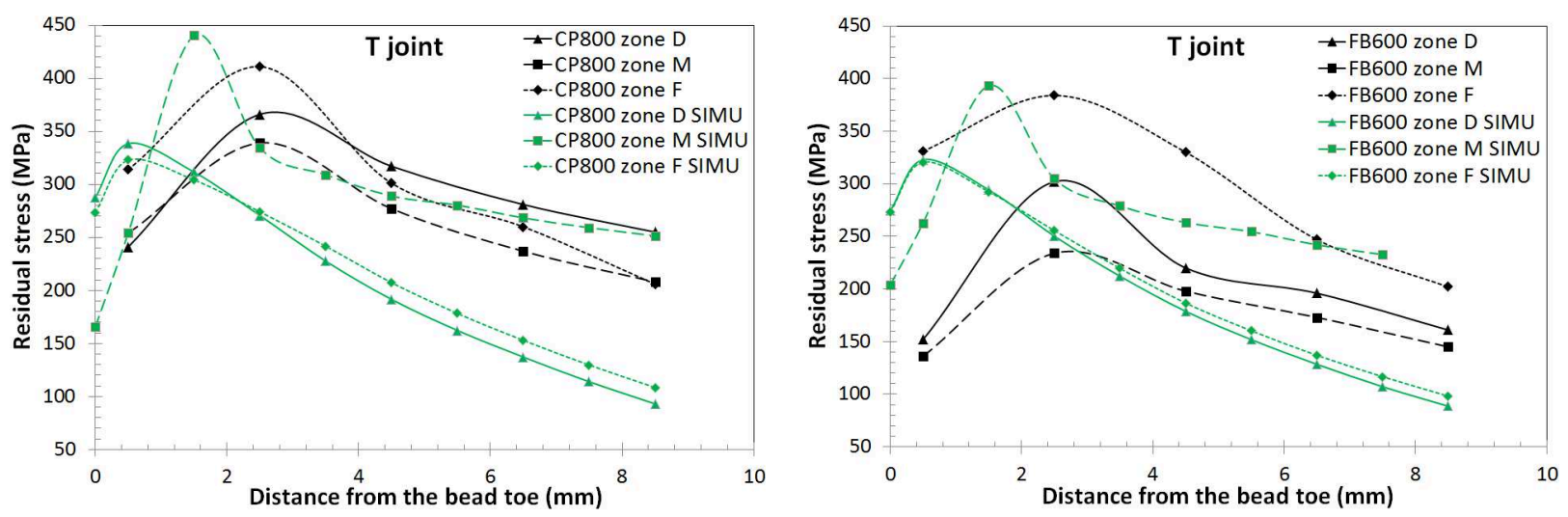

Figure 4. Comparison between simulation and experimental residual stress evolution according to the distance from the bead toe for the case of the as-welded $\mathrm{T}$ joint specimens.

Unlike experimental results, numerical residual stress values show a very slight difference between the beginning (zone D) and the end (zone F) of the welding bead. It is worth emphasising that simulation results can only be admitted in a qualitative context. In a quantitative point of view, values of residual stress obtained by simulation remain to be improved.

\section{Residual stress effect on fatigue lifetime}

In order to characterise the residual stress effect on fatigue lifetime, fatigue tests have been conducted on both specimen batches (as-welded specimens and heat treated stress relaxed specimens). In this paper, only results of the $\mathrm{T}$ joint specimens are presented. The lower sheet of Tshaped specimens is embedded at the hatched area (cf. Fig. 1$)$ and a cyclic loading $(R=0.1, f=10$ $\mathrm{Hz}$ ) is applied on the upper sheet, as shown in Fig. 1. The graphic of Fig. 5 shows that residual stress has almost no effect on the fatigue lifetime. This phenomenon can be physically explained by the crack-like weld bead toe that creates a high stress concentration.

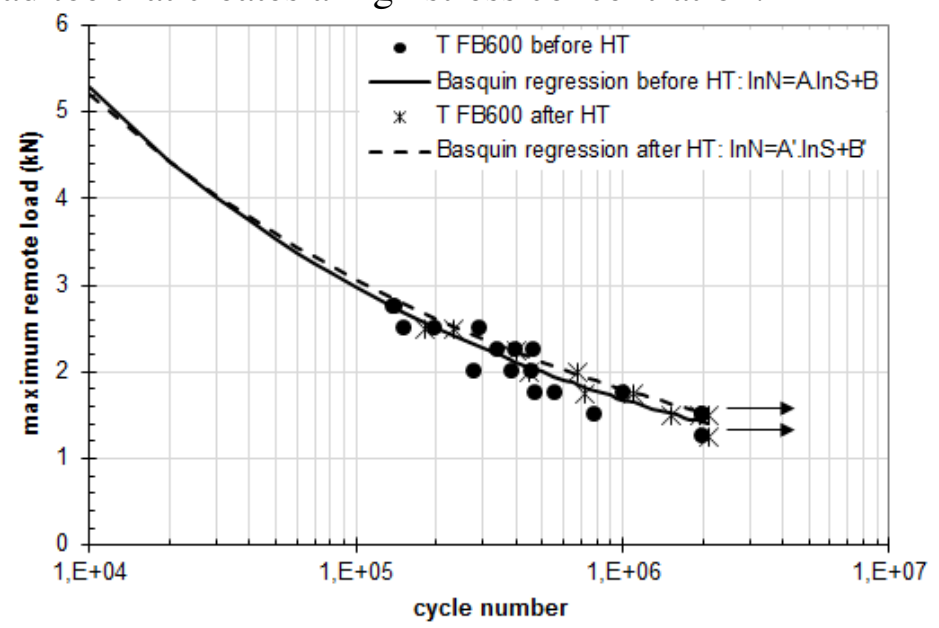

Figure 5. Fatigue life curves under constant amplitude loading for FB600 T joint specimen before and after residual stress relief heat treatment.

In fact, using elastic finite element simulations, the evolution of the normal stress (stress calculated in the direction normal to the welding bead) according to the distance from the bead toe, has been dressed. Accordingly, the $\mathrm{T}$ joint normal stress concentration factor has been estimated and found to be equal to 8.2. Thus, the stress concentration is of such amplitude that it generates cyclic inelastic strain during fatigue loading, thereby relaxing the tensile residual stresses even in the high cycle fatigue range (low load level). Several authors [1-6] have reported welding residual stress relaxation phenomenon in the low cycle fatigue range (high load level) for different welding joint types. The stress concentration factors of the welding joint types used in these studies go from 2 to 5 . Unlike Fig. 5 results, these authors have shown that, in the high cycle fatigue range, the 
fatigue life of stress relieved specimens becomes higher than that of the untreated specimens. The difference between the results found in literature and our results can be explained by the higher bead toe stress concentration factor observed in our case.

\section{Conclusions}

MAG welding induced residual stresses reach their peak values at the end of the weld bead. Welding process simulation under Sysweld allows a good prediction of the HAZ and the weld pool shapes. Numerically calculated residual stress fields are only satisfactory for a qualitative comparison; they have to be improved for quantitative issues. Fatigue tests have shown that welding induced tensile residual stresses have almost no effect on the fatigue life. This phenomenon has been explained by the fact that the crack-like weld toe creates a large stress concentration that causes very high stress amplitudes sufficient to generate cyclic plastic strain during fatigue loading and then to eliminate the residual stress. Accordingly, stress relief heat treatment can be dropped for components submitted to fatigue loading, as cyclic inelastic strain at the weld toe will have already removed the tensile residual stresses after few loading cycles.

\section{References}

[1] T.N. Nguyen, M.A. Wahab, The effect of weld geometry and residual stresses on the fatigue of welded joints under combined loading, Journal of Materials Processing Technology, Volume 77, Issues 1-3, 1 May 1998, Pages 201-208.

[2] C.M. Sonsino, Effect of residual stresses on the fatigue behaviour of welded joints depending on loading conditions and weld geometry, International Journal of Fatigue, Volume 31, Issue 1, January 2009, Pages 88-101.

[3] L.L. Martinez, R.L. Peng, A.F. Blom, D.Q. Wang, Welding and tig-dressing induced residual stresses- relaxation and influence on fatigue strength of spectrum loaded weldments, In: G. Marquis and J. Solin, Editor(s), European Structural Integrity Society, Elsevier, 1999, Volume 23, Pages 117-133.

[4] X. Cheng, J.W. Fisher, H.J. Prask, T. Gnäupel-Herold, B.T. Yen, S. Roy, Residual stress modification by post-weld treatment and its beneficial effect on fatigue strength of welded structures, International Journal of Fatigue, Volume 25, Issues 9-11, September-November 2003, Pages 1259-1269.

[5] D. Tawfik, P.J. Mutton, W.K. Chiu, Experimental and numerical investigations: Alleviating tensile residual stresses in flash-butt welds by localised rapid post-weld heat treatment, Journal of Materials Processing Technology, Volume 196, Issues 1-3, 21 January 2008, Pages 279291.

[6] M. Takanachi, K. Kamata, K. Iida, Relaxation des contraintes résiduelles de soudage par sollicitation en fatigue d'assemblages soudés bout à bout, Soudages et Techniques connexes, Juillet-Août 2001.

[7] M. Mochizuki, Control of welding residual stress for ensuring integrity against fatigue and stress-corrosion cracking, Nucl. Eng. Des. 237 (2) (2007), 107-123.

[8] P. Ferro, H. Porzner, A. Tiziani, F. Bonollo, The influence of phase transformations on residual stresses induced by the welding process $-3 \mathrm{D}$ and 2D, numerical models, Model. Simul. Mater. Sci. Eng. 14 (2006) 117-136.

[9] J.B. Leblond and J.C. Devaux, A new kinetic model for anisothermal transformation metallurgical transformations in steel including effect of austenite grain size, Acta Metallurgica, 32, 1, p137-146, 1984.

[10] J.B. Leblond and J.C. Devaux, Mathematical modelling of transformation plasticity in steels. I : Case of ideal plastic phases, International Journal of Plasticity, vol5, 1996.

[11] J.B. Leblond and J.C. Devaux, Mathematical modelling of transformation plasticity in steels. II : Coupling with strain hardening phenomena, International Journal of Plasticity, vol5, 1996.

[12] P. Tekriwal, J. Mazumder, Transient and residual thermal strain-stress analysis of GMAW, ASMEJ Eng. Mater. Technol. 113 (1991) 336-343. 